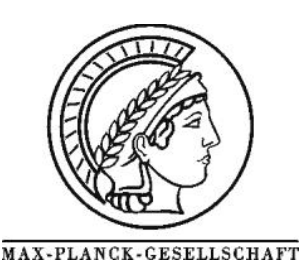

\title{
Structure and electrical conductivity of porous zirconium titanate ceramics produced by mechanochemical treatment and sintering
}

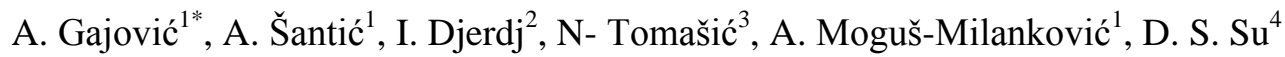 \\ ${ }^{1}$ Ruđer Bošković Institute, 10002 Zagreb, Croatia \\ ${ }^{2}$ ETH Zürich, Department of Materials, 8093 Zürich, Switzerland \\ ${ }^{3}$ Institute of Mineralogy and Petrography, Faculty of Science, University of Zagreb, 10000 Zagreb, Croatia \\ ${ }^{4}$ Fritz-Haber-Institut der Max-Planck-Gesellschaft, D-14195 Berlin, Germany
}

*Corresponding author: e-mail gajovic@irb.hr,

Received 24 September 2008; revised 21 December 2008; accepted 27 December 2008. Available online 6 January 2009.

\begin{abstract}
High-energy ball milling has been employed for mechanochemical treatment of $\mathrm{TiO}_{2}$ and $\mathrm{ZrO}_{2}$, thus facilitated the solid-state reaction toward $\mathrm{ZrTiO}_{4}$. The ceramics with different degrees of porosity were prepared by $8 \mathrm{~h}$ sintering of thus prepared nanopowder precursor at 1100,1200 , 1300 and $1400{ }^{\circ} \mathrm{C}$. The solid-state reaction was completed after sintering at $1200{ }^{\circ} \mathrm{C}$.

The correlation between the structure of $\mathrm{ZrTiO}_{4}$ ceramic (ZT) at the nano-scale and its electric response at different humidities was studied. Highly porous ZT ceramics sintered at 1100 and $1200{ }^{\circ} \mathrm{C}$ showed significant difference in electrical conductivity depending on atmosphere conditions indicating promising application as humidity sensors.
\end{abstract}

Keywords: $\mathrm{ZrTiO}_{4}$ ceramics, Mechanochemical processing Sintering Crystal structures

\section{Introduction}

Ceramics based on $\mathrm{ZrTiO}_{4}(\mathrm{ZT})$ have attracted a great interest in a variety of electronic applications where low loss and temperature stable dielectric materials are required [1-3]. Their specific electrical/dielectric properties are closely related to the microstructure. It was reported [1, 2], that ZT ceramics sintered without additives to the dense bodies of (96-98\% theoretical density) show very good microwave dielectric properties $\left(Q ; \varepsilon_{\mathrm{r}}\right)$, which makes them attractive material in the mobile networks technologies and satellite communication as a phase shifters, voltage tunable oscillators and filters. As the relative density of the ceramics decreases, both $\varepsilon_{\mathrm{r}}$ and $\mathrm{Q}$ decrease due to the effect of polarization at the pore surface [3], which consequently limits their use as a dielectric material.

On the other hand, porous ZT ceramics possesses humidity sensing ability [4-6]. Generally, humidity sensors based on ceramics and polymers are widely used for monitoring and controlling various domestic and industrial surroundings. In comparison to polymers, ceramic sensors show several technical advantages: a high mechanical strength, chemical resistance and thermal stability in combination with high sensitivity [4]. Most of the commercial ceramic humidity sensors are based on the changes of resistance or capacitance of porous sintered oxides at different environmental humidities. The sensitivity and stability of sensing are related to the size and shape of the pores in porous structure of the ceramics [4, 5]. Although number of studies [4-6] on humidity sensing properties of porous ZT ceramics prepared by different techniques have been reported, investigation of this ceramic system in order to obtain highly sensitive, selective and reliable sensors which are cheap, compact and microprocessor compatible still represents challenging topic. 
Since the microstructure of ceramics strongly depends on the preparation route, the choice of the preparation procedure is usually based on the potential usage of the ceramics. Basically, porous ZT ceramics can be prepared using the conventional solid state reaction by means of thermal methods in combination with low-energy mechanical treatment [7-9]. In order to achieve a solid state reaction, a few heating cycles at temperatures around $1600{ }^{\circ} \mathrm{C}$ combined with mechanical grinding in between are necessary. Additionally, to obtain a solid state reaction at lower temperatures, additives such as $\mathrm{ZnO}, \mathrm{NiO}, \mathrm{Fe}_{2} \mathrm{O}_{3}$ and $\mathrm{La}_{2} \mathrm{O}_{3}$ are usually used. In recent years a permanent need for suppression of energy consumption accompanied by the high temperature sintering, has led to the development of various chemical routes such as sol-gel synthesis [6] or polymeric precursor technique [5]. However, all mentioned approaches for the preparation of ZT ceramics presume expensive preparation procedures inappropriate for mass production.

Recently, we have shown $[10,11]$ that the preparation of ZT ceramics from the ball milled precursor decreases the sintering temperature and thus reduces the energy necessary for solid state synthesis of pure ZT ceramics. In fact, the powder precursor produced by highenergy ball milling of $\mathrm{TiO}_{2}$ and $\mathrm{ZrO}_{2}$, facilitates the solid state reaction toward $\mathrm{ZrTiO}_{4}$ even before heat treatment [10]. Accordingly, this preparation procedure represents a relatively simple and cheap route which excludes need for additives, providing no impurities in the final product.

The aim of this study is to investigate structural properties of porous ZT ceramics prepared by sintering of ball milled powder precursor at relatively low temperatures from 1100 to $1400{ }^{\circ} \mathrm{C}$. Different porosity was achieved by changing the sintering temperature. The structure of the ceramics was thoroughly studied by combining different techniques, Raman spectroscopy (RS), X-ray powder diffraction (XRD), scanning electron microscopy (SEM) and high resolution transmission electron microscopy (HRTEM). The relationship between ZT ceramic structure at the nano-scale and electric response in different atmospheres were investigated. The electrical response was examined by DC conductivity measurements and impedance spectroscopy.

\section{Experimental}

High-energy ball milling was used for the mechanochemical treatment of equimolar mixture of anatase $\mathrm{TiO}_{2}$ (crystallite sizes 76(3) nm) and monoclinic $\mathrm{ZrO}_{2}$ (crystallite sizes 63(3) $\mathrm{nm}$ ) [10]. The milling was performed in air by planetary ball-mill (Fritsch, "Pulverisette 6") with vial and balls made of zirconia. The powder-to-ball weight ratio was chosen to be $\mathrm{R}=1: 10$ to avoid contamination due to wearing of milling media [11]. The samples were milled with the rotation speed of $500 \mathrm{rpm}$ for $7 \mathrm{~h}$, since at this milling time began the solid state reaction toward $\mathrm{ZrTiO}_{4}[10]$. The crystallite sizes of $7 \mathrm{~h}$ milled powder were between 5 and $7 \mathrm{~nm}$, as is shown in our previous work [10]. The ball-milled powder was the mixture of high pressure $\mathrm{TiO}_{2}$ II phase (48.7 wt \%), monoclinic $\mathrm{ZrO}_{2}\left(28.7\right.$ wt \%), $\mathrm{ZrTiO}_{4}(5.3 \mathrm{wt}$ $\%)$ and amorphous phase (17.3 wt \%) [10].

Prior to sintering the ball milled powder precursor was compacted at $180 \mathrm{MPa}$. The ZT ceramics were prepared by sintering in air for $8 \mathrm{~h}$ at 1100 (ZT-1100), 1200 (ZT-1200), 1300 (ZT-1300) and $1400{ }^{\circ} \mathrm{C}$ (ZT-1400) using muffle furnace ("Over-industrijska elektronika”). Heating rate was $23{ }^{\circ} \mathrm{C} / \mathrm{min}$ for all sintering temperatures.

Raman spectroscopy (RS) was performed by Raman system (Jobin Yvon T64000) working in micro Raman, triple monochromator mode. An argon ion laser (Coherent, Innova 400, Santa Clara, CA) operating at $514.5 \mathrm{~nm}$ with a laser power of $20 \mathrm{~mW}$ at the samples for excitation.

The XRD measurements were obtained by Philips PW 3040/60 X'Pert PRO powder diffractometer, employing $\mathrm{CuK} \alpha$ radiation at $45 \mathrm{kV}$ and $40 \mathrm{~mA}$. The incident beam was passed through an X-ray mirror having divergence slit of $0.5^{\circ}$. The diffracted beam was directed to the detector through the parallel plate collimator with equatorial acceptance angle of $0.18^{\circ}$. The step size was $0.02^{\circ}$ with measuring time of $20 \mathrm{~s} / \mathrm{step}$.

The structural and microstructural parameters of ceramics samples were extracted using Rietveld refinement with the program FULLPROF [12]. The scale factor, the background coefficients, the zero point of the detector, and the unit cell parameters were in the first step simultaneously refined, followed by the refinement of the Gaussian half width parameters, $U, V, W$, and the Lorentzian halfwidth parameters, $X, Y$. The employed profile function was chosen to be the modified Thompson-Cox-Hastings pseudo-Voigt [13], making the size-microstrain analysis straightforward. The crystal structure was refined in the space group of Pnab (60) for $\mathrm{ZrTiO}_{4}, \mathrm{P}_{2} / \mathrm{mnm}$ (136) for $\mathrm{TiO}_{2}$ rutile and $P 2_{1} / c$ (14), for monoclinic $\mathrm{ZrO}_{2}$. The quality of Rietveld refinement was evaluated in terms of the discrepancy factor (weighted residual error), $R_{w p}$, Bragg discrepancy factor, $R_{B}$, and the goodness-of-fit indicator, GoF. The determination of the volume-weighted average grain sizes $(D)$ and the average maximum microstrain $(e)$ was achieved by the line-broadening analysis $[14,15]$. The instrumental contribution to the peak broadening was removed by the deconvolution method using crystalline $\mathrm{CeO}_{2}$ as a standard.

The morphology and size of sintered grains in ZT ceramics were studied by scanning electron microscope, SEM, JEOL T300, operated at $25 \mathrm{kV}$. The structure of the crystallites ( $=$ coherently diffracting domains) inside the sintered grains and structure of the grain boundaries were observed using high resolution TEM (HRTEM) and were performed by Philips CM200 $\mathrm{LaB}_{6}$ and FEG microscopes both operated at $200 \mathrm{kV}$. The TEM samples were prepared by polishing and ion beam thinning.

The electrical characterization was performed using DC conductivity measurements. The DC conductivity, $\sigma_{\mathrm{DC}}$, of the samples was measured as a function of temperature from 297 to $500 \mathrm{~K}$ with heating rate of $5 \mathrm{~K} / \mathrm{min}$ in different 
atmospheres, air and dry nitrogen. The measurements were performed using a DC bias of $100 \mathrm{~V}$ and the resulting current was measured using a digital electrometer (Keithley 6514). For the electrical contact, gold electrodes $3 \mathrm{~mm}$ in diameter were sputtered onto both sides of the sample discs (SC7620 Sputter Coater). All sample discs were $1 \mathrm{~mm}$ thick with diameter of $4 \mathrm{~mm}$. From the measured electrical resistance $\mathrm{R}$ and electrode dimensions (where $\mathrm{A}$ is the electrode area and $\mathrm{d}$ is thickness of the sample), DC conductivity $\sigma_{\mathrm{DC}}$, of the samples was calculated using the equation $\sigma_{\mathrm{DC}}=\mathrm{d} /(\mathrm{R} \cdot \mathrm{A})$

Selected ceramic samples, namely ZT-1100 and ZT1200 , were examined by impedance spectroscopy in a sample chamber with controlled relative humidity. The different relative humidities $(\mathrm{RH})$ inside the sample chamber were obtained using saturated aqueous solutions of different salts: $\mathrm{MgCl}_{2}(\mathrm{RH} \approx 33 \%) \mathrm{NaBr}(\mathrm{RH} \approx 56 \%)$ and $\mathrm{NaCl}$ $(\mathrm{RH} \approx 75 \%)$. The impedance was measured in the frequency range from $0.01 \mathrm{~Hz}$ to $10 \mathrm{MHz}$ (Novocontrol Alpha analyzer) at $297 \mathrm{~K}$ and the experimental data were analyzed by equivalent circuit modeling using the complex nonlinear least square (CNLLSQ) fitting procedure.

\section{Results}

\subsection{Raman spectroscopy}

Raman spectrum of the ceramics sintered at $1100{ }^{\circ} \mathrm{C}$ (Fig. 1, ZT-1100) indicates that solid state reaction has not been finished after $8 \mathrm{~h}$ of sintering in air. In this spectrum intensive rutile $\left(\mathrm{TiO}_{2}\right)$ bands at 432 and $612 \mathrm{~cm}^{-1}$ dominate. The rutile bands at 144 and $233 \mathrm{~cm}^{-1}$ are observed as shoulders in addition to two bands of monoclinic $\mathrm{ZrO}_{2}$ appearing at 178 and $192 \mathrm{~cm}^{-1}$. Together with rutile and $\mathrm{m}$ $\mathrm{ZrO}_{2}$ bands, a few bands of $\mathrm{ZrTiO}_{4}$ can be observed: two prominent bands at $254,339 \mathrm{~cm}^{-1}$, and barely detectible bands at 646 and $799 \mathrm{~cm}^{-1}$.

The solid state reaction was completed after sintering at $1200{ }^{\circ} \mathrm{C}$, so the observed Raman spectrum shows only $\mathrm{ZrTiO}_{4}$ bands at 134, 162, 262, 339, 405, 541, 591, 646, 716 and $799 \mathrm{~cm}^{-1}$ (Fig. 1, ZT-1200). $\mathrm{ZrTiO}_{4}$ crystallizes with Pnab space group and $\alpha-\mathrm{PbO}$ structure type, having two formula units in unit cell. Thus, $\mathrm{ZrTiO}_{4}$ has 33 optically active modes of vibration of which 18 are Raman active modes [16]. We observed lower number of the bands, which can be explained by overlapping of the broadened bands. The randomly distributed cations $\mathrm{Zr}^{4+}$ and $\mathrm{Ti}^{4+}$ within $M$-site in the crystal structure influence the band broadening. Moreover, since the ceramics was prepared from high-energy ball milled precursor, the oxide defects and nonstoichiometric variations of $\mathrm{Zr} / \mathrm{Ti}$ ratio are also expected $[16,17]$. In the Raman spectrum of ZT-1300 ceramics the bands at $330,345 \mathrm{~cm}^{-1}$ become resolved and the band at $716 \mathrm{~cm}^{-1}$ is slightly more intense (Fig. 1) which indicates higher ordering due to possible small amount of low-temperature $\mathrm{ZrTiO}_{4}$ phase of high structural order. The weak band at $284 \mathrm{~cm}^{-1}$ is resolved only in the Raman

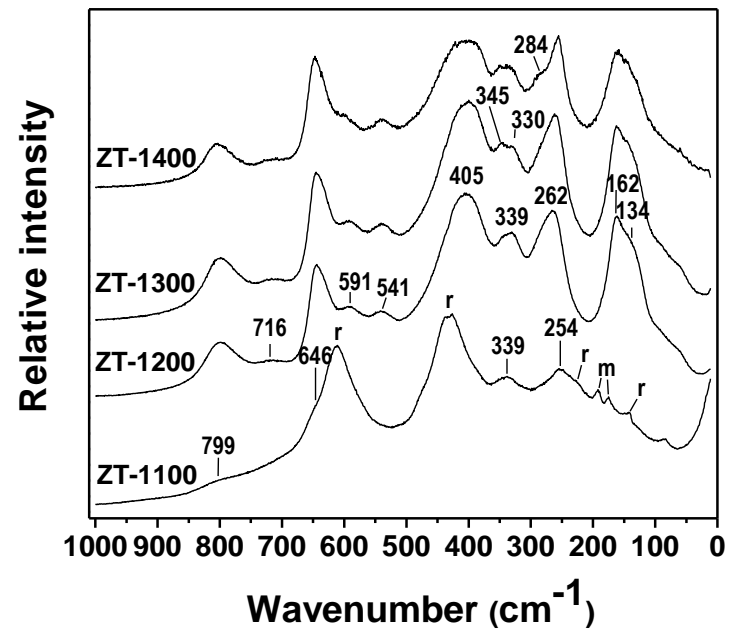

Fig. 1: Raman spectra of ceramics sintered at 1100, 1200, 1300 and $1400{ }^{\circ} \mathrm{C}(\mathrm{ZT}-1100$, ZT-1200, ZT-1300 and ZT-1400, respectively). Numbers above spectra denote the band wavenumbers of the $\mathrm{ZrTiO}_{4}$, $\mathrm{r}$ denotes $\mathrm{TiO}_{2}$ rutile, $\mathrm{m}$ denotes monoclinic $\mathrm{ZrO}_{2}$.

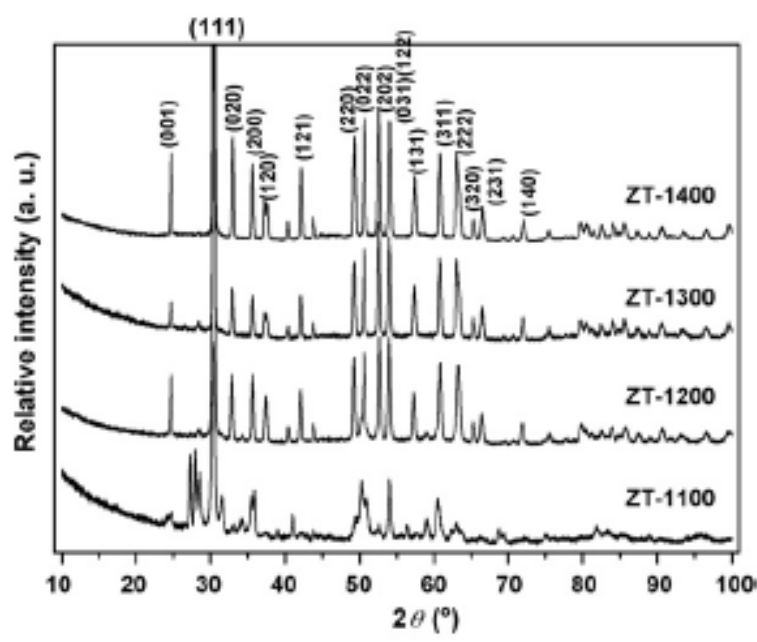

Fig. 2: XRD patterns of ceramics sintered at the denoted temperatures. Miller indices of $\mathrm{ZrTiO}_{4}$ are indicated above the pattern.

spectrum of ceramics sintered at $1400{ }^{\circ} \mathrm{C}$ (ZT-1400), thus suggesting complete densification of the ceramics.

\subsection{X-ray powder diffraction}

The powder XRD patterns of the examined samples are depicted in Fig. 2, while the results of Rietveld analysis are summarized in Table 1 . The XRD patterns point to a high crystallinity of all ZT ceramics. The observed Bragg peaks are undoubtedly identified as $\mathrm{ZrTiO}_{4}$ for the samples ZT-1200, 1300, 1400, whereas the sample ZT-1100 contains rutile $\mathrm{TiO}_{2}$ and monoclinic $\mathrm{ZrO}_{2}$ beside major $\mathrm{ZrTiO}_{4}$ phase. The phase content of $\mathrm{ZrTiO}_{4}$ calculated by Rietveld refinement of XRD powder patterns (Table 1) is $54.4 \mathrm{wt}$. \% indicating that the solid state reaction has not been completed yet in the sample sintered at $1100^{\circ} \mathrm{C}$. 
Table 1: Structural data and refinement parameters fot ZT ceramics calculated by Rietveld refinement of XRD powder patterns, $\mathrm{V}_{\mathrm{c}^{-}}$ cell volume, $\mathrm{D}$-isotropic average crystallite size, $e$-average maximum microstrain, and $\mathrm{R}_{\mathrm{wp}}$ weight residual error.

\begin{tabular}{|c|c|c|c|c|}
\hline Sample & 2T-1100 & ZT- 1200 & 2T- 1300 & ZT- 1400 \\
\hline $\begin{array}{l}\text { Space group } \\
\text { Phase }\end{array}$ & $\begin{array}{l}\text { Pnab (60) } \\
\mathrm{ZrTiO}_{4}\end{array}$ & $\begin{array}{l}\text { Phab (60) } \\
\mathrm{ZrTiO}_{4}\end{array}$ & $\begin{array}{l}\text { Pnab (60) } \\
\mathrm{Z}_{\mathrm{rTiO}}\end{array}$ & $\begin{array}{l}\text { Pnab (60) } \\
\mathrm{ZrTiO}_{4}\end{array}$ \\
\hline Lattice parameter (A) & $\begin{array}{l}a-5,040(1) \\
b=5,387(1) \\
c=4,824(1)\end{array}$ & $\begin{array}{l}a-5,033(1) \\
b=5,442(2) \\
c=4,806(1)\end{array}$ & $\begin{array}{l}a=5,036(1) \\
b=5,433(1) \\
c=4,815(1)\end{array}$ & $\begin{array}{l}a=5,036(1) \\
b=5,425(2) \\
c=4,815(1)\end{array}$ \\
\hline $\begin{array}{l}V_{C}\left(A^{3}\right) \\
D(n m) \\
e\left(\times 10^{4}\right)\end{array}$ & $\begin{array}{l}130,96(5) \\
15,9 \\
8,258\end{array}$ & $\begin{array}{l}131,63(4) \\
89,9 \\
25,355\end{array}$ & $\begin{array}{l}131,74(5) \\
67,9 \\
17,002\end{array}$ & $\begin{array}{l}131,54(3) \\
178,8 \\
26,350\end{array}$ \\
\hline Phase & $\begin{array}{l}54,4 \mathrm{ZrTiO}_{4} \\
38,9 \mathrm{r}-\mathrm{TiO}_{2} \\
6,7 \mathrm{~m}-\mathrm{ZrO}_{2}\end{array}$ & $100 \mathrm{ZrTO}_{4}$ & $100 \mathrm{ZTiO}_{4}$ & $100 \mathrm{ZrTiO}_{4}$ \\
\hline Composition (wt\&) & 15,4 & 152 & 16.6 & 16.8 \\
\hline
\end{tabular}

The extracted lattice parameters of $\mathrm{ZrTiO}_{4}$ are in agreement with the reported values for $\mathrm{ZrTiO}_{4}$ (JCPDS No. 34-0415). In the samples containing only $\mathrm{ZrTiO}_{4}$, the slight decrease of parameter $b$ with increase of sintering temperature was observed, thus indicated very small amount of ordered low-temperature phase $[8,9]$. The peak broadening is isotropic, i.e. $h k l$ dependence was not observed. The calculated values of average crystallite size as well as average maximum microstrain show dependence on sintering temperature. From Table 1, one can see that the increase of sintering temperature from 1100 to $1200{ }^{\circ} \mathrm{C}$ results in a significant enlargement of crystallite size of almost six times, while at the same time the lattice microstrain is increased by the factor 3 . Further increase of sintering temperature up to $1300{ }^{\circ} \mathrm{C}$ shows an anomaly in both calculated parameters, i.e. their values are lower in comparison with ceramics sintered at $1200{ }^{\circ} \mathrm{C}$. Such a behavior is rather unusual and it represents deviation from normal response of a powdered precursor to the increase of sintering temperature. The final sample sintered at $1400{ }^{\circ} \mathrm{C}$ again shows regular growth of crystallites and slight increase of microstrain. Considering the "regular ceramics", the one not accounting for ZT-1300, the increase of microstrain with the increase of sintering temperature indicates the enhancement of defects concentration within the crystalline lattice or more probably in grain boundaries.

\subsection{Electron microscopy (SEM and TEM)}

SEM images show homogenously porous material in ceramics sintered at 1100,1200 and $1300{ }^{\circ} \mathrm{C}$ (Fig. 3a-c). Lower porosity and larger sintered grains were obtained at higher sintering temperatures. Therefore, the surfaces of ZT-1100 and ZT-1200 seem similar having separated sintered grains (Fig. 3a and b) but ZT-1100 has sintered grains much below $1 \mu \mathrm{m}$. The grain growth at $1200{ }^{\circ} \mathrm{C}$ yields the grains of almost $1 \mu \mathrm{m}$ in size. The pore phase is extensive and continuous in both samples with the similar pore sizes. In material sintered at $1300{ }^{\circ} \mathrm{C}$ (Fig. 3c) the sintered grains continue to enlarge and become welded making a continuous ceramic structure, and thus causing the ability for closing the pores inside the material.

On the other hand, ZT-1400 ceramics (Fig. 3d) is almost completely sintered, what has been already indicated by a strong shrinkage of the sample observed after sintering at $1400{ }^{\circ} \mathrm{C}$. The sintered grains become larger than $5 \mu \mathrm{m}$ with small number of pores which are completely closed inside the materials (Fig. 3d, inset).
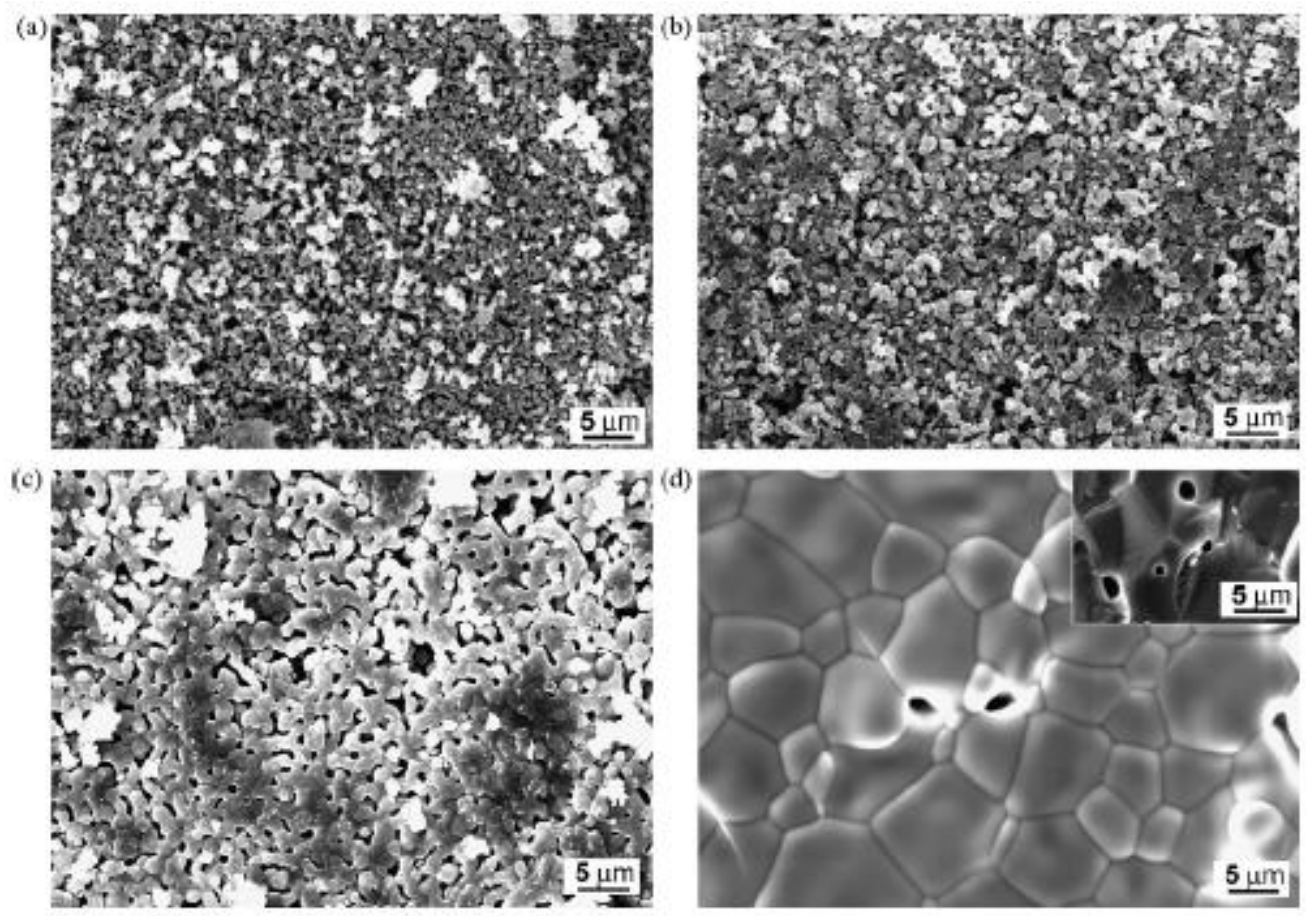

Fig. 3: SEM of ceramics sintered at: (a) $1100^{\circ} \mathrm{C}$ (ZT-1100), (b) $1200^{\circ} \mathrm{C}(\mathrm{ZT}-1200)$, (c) $130 \circ^{\circ} \mathrm{C}(\mathrm{ZT}-1300)$ and (d) $1400{ }^{\circ} \mathrm{C}(\mathrm{ZT}-$ 1400) within set showing closed pores within the sample. 

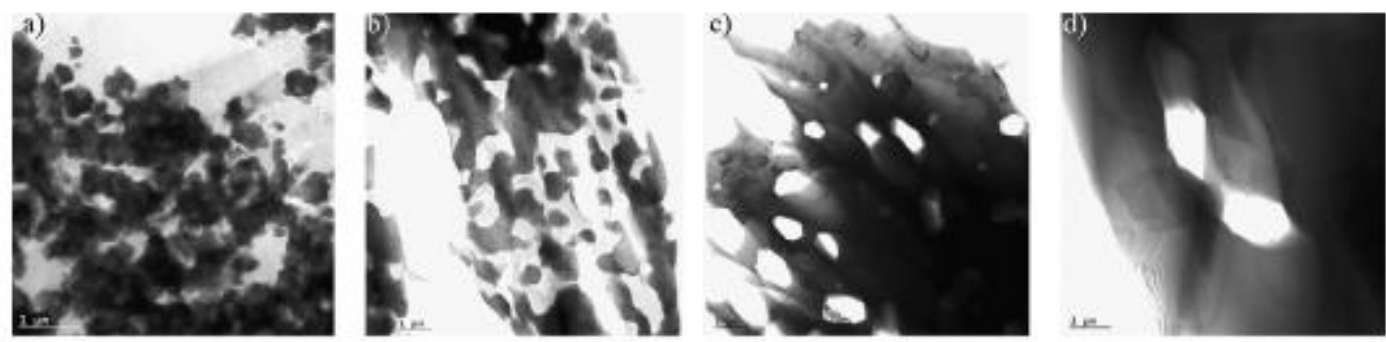

e)

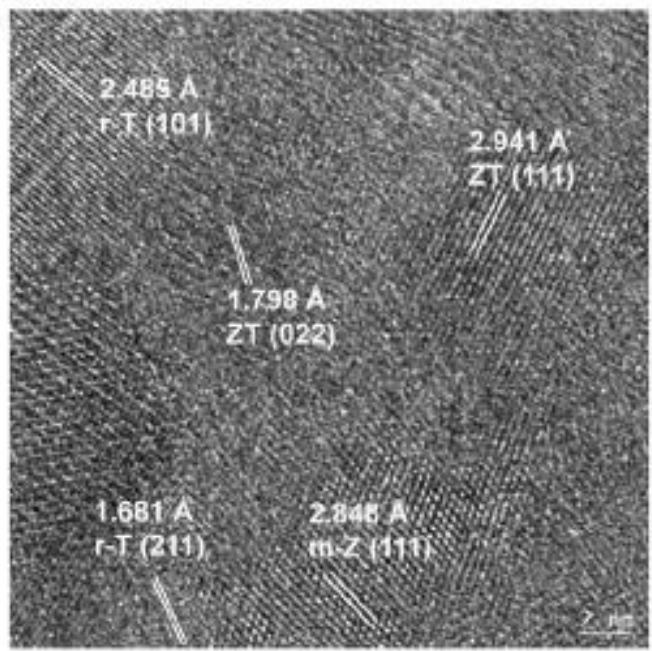

g)

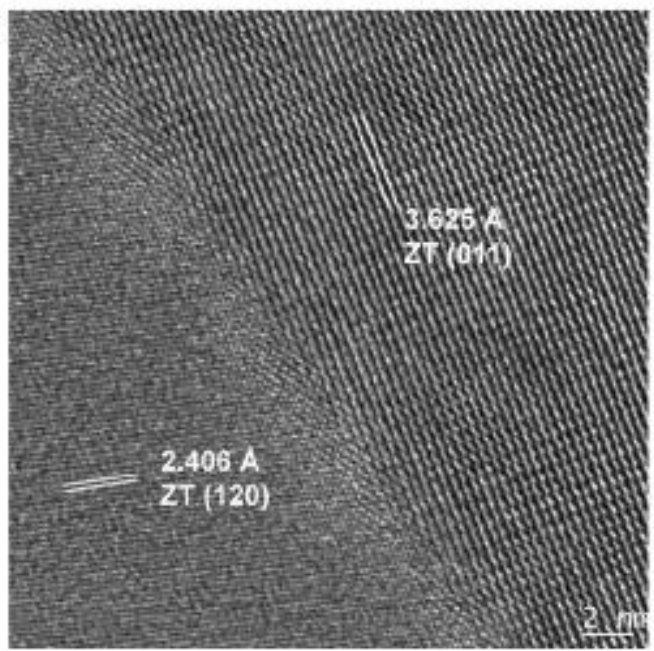

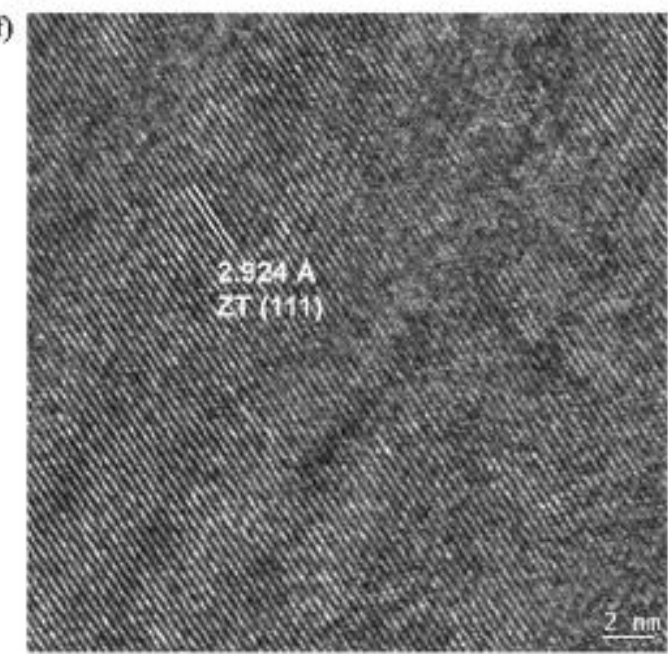

h)

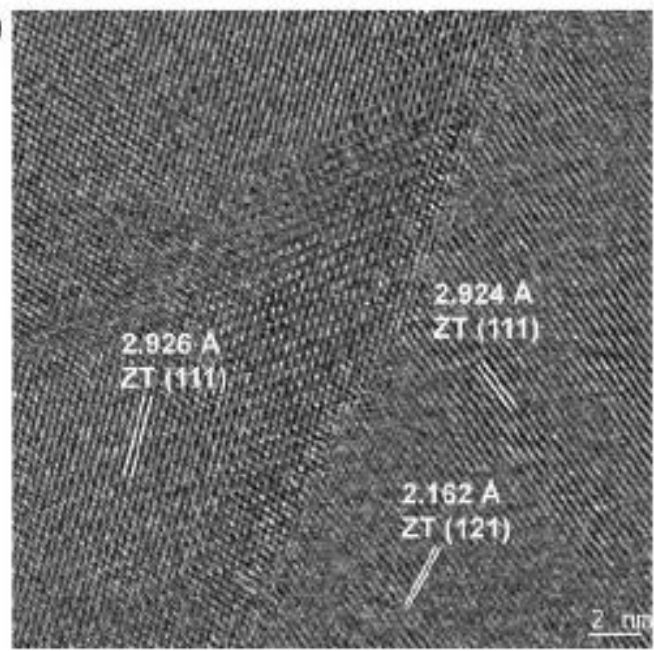

Fig. 4: TEM images of ceramics sintered at : (a) $1100^{\circ} \mathrm{C}$, (b) $1200^{\circ} \mathrm{C}$, (c) $1300^{\circ} \mathrm{C}, \mathrm{d} 1400^{\circ} \mathrm{C}$ and HRTEM images of sintered at: (e) $1100^{\circ} \mathrm{C}$, (f) $1200^{\circ} \mathrm{C},(\mathrm{g}) 1300^{\circ} \mathrm{C}$, and (h) $1400^{\circ} \mathrm{C}$.

TEM micrographs of the ion beam thinned ceramics support the SEM observations (Fig. 4a-d) and clarify the changes of microstructure with sintering temperature. ZT1100 ceramics has poorly linked small sintered grains (Fig. 4a). TEM of ZT-1200 shows connected sintered grains with a few evident defects. The pores are about $0.5 \mu \mathrm{m}$ large and open (Fig. 4b), while after sintering at $1300{ }^{\circ} \mathrm{C}$ some pores become closed inside the material (Fig. 4c). In the ZT-1300 ceramics no defects were observed in the grains or grain boundaries. This result partially support the low microstrain obtained from XRD measurements. In ZT-1400 ceramics only the closed pores are observed (Fig. 4d).

HRTEM shows multi-phase character of ZT-1100 ceramics at the nanoscale (Fig. 4e), thus the formed sintered grains are polycrystalline with small crystallite sizes.
The ceramics sintered at higher temperatures; 1200, 1300 and $1400{ }^{\circ} \mathrm{C}$ contain only $\mathrm{ZrTiO}_{4}$ with larger crystallites. Therefore, in ZT-1200 some sintering grains grow to be single crystals (Fig. 4f). In ZT-1300 ceramics the majority of the grain boundaries are well defined like the one representative shown in Fig. 4g, while in the ceramics sintered at $1400{ }^{\circ} \mathrm{C}$ certain defects were observed at some grain boundaries (Fig. 4h). The resolved lattice fringes of the identified phases with corresponding Miller indices are denoted in Figs. 4e-h. 

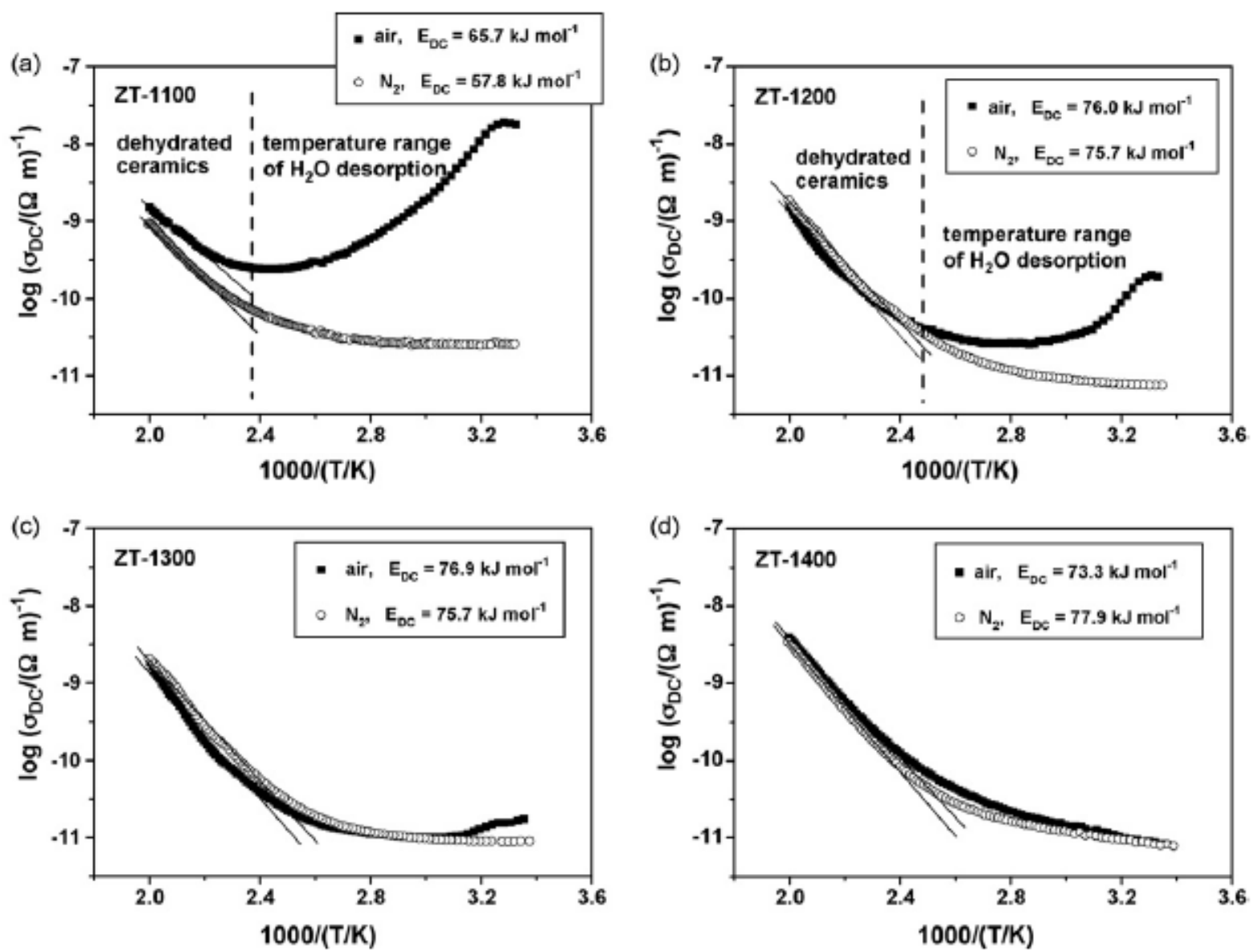

Fig. 5: Arrhenius plots of $\sigma_{\mathrm{dc}}$ for ZT ceramics sintered at: (a) $1100{ }^{\circ} \mathrm{C}$, (b) $1200{ }^{\circ} \mathrm{C}$, (c) $1300{ }^{\circ} \mathrm{C}$, and (d) $1400{ }^{\circ} \mathrm{C}$.

\subsection{DC conductivity measurements and imped- ance spectroscopy}

The temperature dependence of DC conductivity, $\sigma_{\mathrm{DC}}$, for ZT ceramics measured in air and dry nitrogen is shown in an Arrhenius type plot of $\log \left(\sigma_{\mathrm{DC}}\right)$ versus $1 / \mathrm{T}$ (Fig. 5). ZT ceramics sintered at 1100 and $1200{ }^{\circ} \mathrm{C}$ exhibit a significant difference in $\sigma_{\mathrm{DC}}$ depending on atmosphere. On the other hand, ZT-1300 ceramics shows very small difference in $\sigma_{\mathrm{DC}}$ in the narrow temperature range above room temperature, whereas for completely sintered ZT1400 ceramics, $\sigma_{\mathrm{DC}}$ measured in air and dry nitrogen is identical over whole experimental temperature range. In the temperature dependence of $\sigma_{\mathrm{DC}}$ in air for ZT-1100, ZT1200 and ZT-1300 ceramics two regions are observed. At lower temperatures, $\sigma_{\mathrm{DC}}$ decreases with increasing temperature due to water desorption, whereas, in high temperature region $\sigma_{\mathrm{DC}}$ increases indicating thermally activated conductivity in dehydrated ceramics. The slope of linear part of $\sigma_{\mathrm{DC}}$ curve in high temperature region corresponds to the activation energy for $\mathrm{DC}$ conductivity, $\mathrm{E}_{\mathrm{DC}}$, according to the Arrhenius relation, $\sigma_{D C}=\sigma_{o} \exp \left(-E_{D C} / k_{B} T\right)$, where $\sigma_{D C}$ is the DC conductivity, $\sigma_{\mathrm{o}}$ is the pre-exponent, $\mathrm{k}_{\mathrm{B}}$ is the Boltzmann constant and $\mathrm{T}$ is the temperature $(\mathrm{K})$. Values of $\mathrm{E}_{\mathrm{DC}}$ are listed in the legends in the Fig. 5.
ZT-1100 ceramics shows highest values of electrical conductivity and wide temperature range of water desorption, up to $\approx 420 \mathrm{~K}$. With increasing sintering temperature to 1200 and $1300{ }^{\circ} \mathrm{C}, \sigma_{\mathrm{DC}}$ measured in air decreases and temperature range of water desorption becomes smaller $(<$ $400 \mathrm{~K}$ and $229 \mathrm{~K}$, respectively). The $\mathrm{E}_{\mathrm{DC}}$ for ZT-1200, ZT1300 and ZT-1400 in air and nitrogen are almost identical, indicating absence of water contribution in conduction processes in dehydrated ceramics. The $\mathrm{E}_{\mathrm{DC}}$ values are close to those previously observed for similarly prepared ZT ceramics [18].

The ceramic samples ZT-1100 and ZT-1200 that display significant difference in $\sigma_{\mathrm{DC}}$ measured in air and dry nitrogen were further examined by impedance spectroscopy under controlled relative humidity $(33 \%, 56 \%$ and $75 \%)$. As illustration, impedance diagrams of ZT-1100 at 56\% and $75 \%$ of relative humidity are shown in Fig. 6 . The impedance spectra consists of single well-shaped semicircle related to the polarization processes in porous ceramics sample, whereas low frequency spur which becomes visible at higher relative humidity (Fig. $6 \mathrm{~b}$ ) is attributed to the effects at the sample-electrode interface [19]. It is well known that the impedance semicircle can be represented by the equivalent circuit consisting of resistor and capacitor in parallel. Ideally, such semicircle passes through the origin of complex plot and gives a low frequency intercept on the 

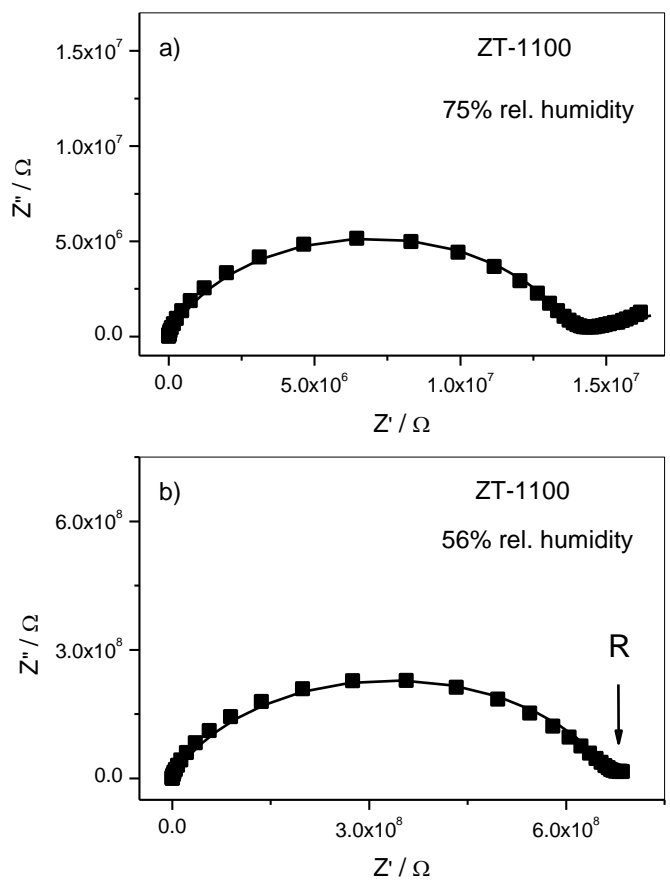

Fig. 6: Complex impedance spectra for ZT-1100 ceramics at $56 \%$ and $75 \%$ of relative humidity.

real axis corresponding to the resistance, $\mathrm{R}$, of the sample. However, experimental data show depressed semicircle with the center below the real axis, which is why the constant-phase element (CPE) is used, rather than ordinary capacitor in equivalent circuits. The CPE is an empirical impedance function of the type: $\mathrm{Z}_{\mathrm{CPE}}{ }^{*}=\mathrm{A}(\mathrm{j} \omega)^{-\alpha}$, where $\mathrm{A}$ and $\alpha$ are the constants. The parameters of the equivalent circuits ( $\mathrm{R}, \mathrm{A}$ and $\alpha$ ) were obtained by the complex nonlinear least square fitting directly to the measured impedance data. The values of the resistance, $\mathrm{R}$ together with electrode dimensions were used to calculate the electrical conductivity. For both ZT-1100 and ZT-1200 ceramics electrical conductivity increases over five orders of magnitude with increasing relative humidity from $33 \%$ to $75 \%$, Fig. 7.

\section{Discussion}

A multiphase character of the ceramics sintered at $1100{ }^{\circ} \mathrm{C}$ is evident by RS, XRD and HRTEM measurements; while a comparison of SEM, HRTEM and XRD corroborate that the formed sintered grains are polycrystalline with small crystalline sizes. The observations obtained by RS, XRD and HRTEM undoubtedly identify the samples sintered at 1200,1300 and $1400{ }^{\circ} \mathrm{C}$ as single phase $\mathrm{ZrTiO}_{4}$. These results clearly point out that nanosized precursors allowed the solid-state reaction to form $\mathrm{ZrTiO}_{4}$ ceramic at a temperature $200^{\circ} \mathrm{C}$ lower than in the case of the conventional solid state syntheses [7-9]. The whole mechanism of lowering reaction temperature in the case of sintering high-energy ball milled precursor is explained in

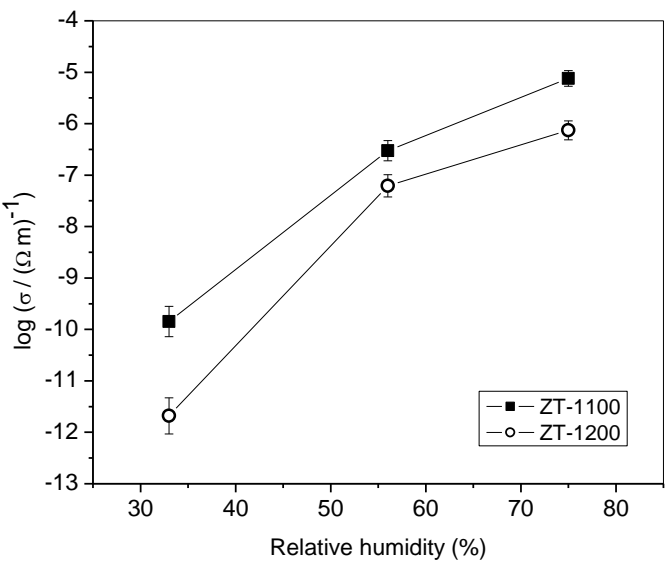

Fig. 7: Electrical conductivity of ZT-1100 and ZT-1200 ceramics at different relative humidities.

details by using Raman, XRD and HRTEM in our previous work [10]. This occurred because formation of $\mathrm{ZrTiO}_{4}$ seeds had already started during milling, while the rest of the sample was mixture of amorphous material, nanosized $\mathrm{TiO}_{2}$ (II) and nanosized $\mathrm{m}-\mathrm{ZrO}_{2}[10]$. The reduction in the activation energy barrier for this solid-state reaction can be explained in view of the simple thermodynamic approach [20].

The morphology of sintered ceramics; sintered grains, pores and crystallites are different in sizes and shapes and dependent on the sintering temperature. Thus, the pores in ZT-1200 ceramics are open as observed by SEM and TEM measurements and of similar sizes as in ZT1100 ceramics. By further increase of sintering temperature to $1300{ }^{\circ} \mathrm{C}$ some pores become closed, while in ZT-1400 ceramic only small number of closed pores was observed. The SEM images show regular growth of sintered grains with increase of temperature from 1100 to $1400{ }^{\circ} \mathrm{C}$. On the contrary, the Rietveld refinement of XRD patterns indicates anomaly for the ceramics sintered at $1300{ }^{\circ} \mathrm{C}$ in both crystallite size and microstrain i.e. their values are lower in comparison with the ceramics sintered at $1200^{\circ} \mathrm{C}$. A higher order in the ZT-1300 ceramics structure is supported by RS measurements, where some Raman bands are better resolved, and HRTEM observations of well defined grain boundaries.

The electrical properties of ZT ceramics measured in different atmospheres follow observed changes in microstructure. For a porous ZT ceramics sintered at 1100 and $1200{ }^{\circ} \mathrm{C}$ electrical conductivity increases drastically as the relative humidity increases from $33 \%$ to $75 \%$ (Fig. 7) revealing very high sensitivity. In porous ceramics, water related conduction occurs as a surface process. The main mechanisms are physical adsorption of water molecules at the grain surface and water condensation in pores depending on relative humidity [21]. At low humidity, water molecules are chemically adsorbed at preferential sites at the grain surface (chemisorbed layer) onto which subsequent layers of water molecules are physically adsorbed (physorbed layer). The physorbed water dissociates due to 
high electrostatic fields in the chemisorbed layer: $2 \mathrm{H}_{2} \mathrm{O} \leftrightarrow$ $\mathrm{H}_{3} \mathrm{O}^{+}+\mathrm{OH}^{-}$, and the charge transport occurs when $\mathrm{H}_{3} \mathrm{O}^{+}$ releases a proton to a neighbouring water molecule which accepts it while releasing another proton, and so forth (Grotthuss chain reaction). At high humidity, liquid water condenses in the pores and electrolytic conduction takes places along with the protonic transport in the adsorbed layers [21].

For ZT-1100 ceramics very high sensitivity to humid atmosphere is related to both the presence of open micropores and multiphase composition. This ceramics has low crystallite and grain size, $15.9 \mathrm{~nm}$ and $<1 \mu \mathrm{m}$ respectively, and therefore large active surface for water adsorption which is reflected in high electrical conductivity in the presence of humidity. With increasing temperature to 1200 and $1300{ }^{\circ} \mathrm{C}$, sintering promotes a larger grain size that leads to decrease of adsorbed water and consequently to a decrease in conductivity. Beside that, a significant number of closed pores observed in ZT-1300 ceramics do not allow water vapor to pass easily through the structure thereby decreasing the water molecule adsorption and humiditysensitive characteristic. Moreover, it is possible that the well-defined grain boundaries and smaller amounts of defects as shown by SEM, HRTEM and XTD additionally decrease the sensing character of this ceramics. Completely sintered ZT-1400 ceramics show no difference in electrical conductivity in air and dry nitrogen due to low porosity and the presence of only completely closed pores that cannot take part in adsorption of water.

\section{Conclusions}

Porous ZT ceramics was prepared by a low cost synthesis route, namely, by the sintering of ball milled powder precursor. Powder precursor produced by high-energy ball

\section{References}

[1] Bianco, G. Gusmano, R. Freer and P. Smith, J. Europ. Ceram. Soc. 19 (1999) 959-963.

[2] Bianco, M. Paci, R. Free, J. Europ. Ceram. Soc. 18 (1998) 1235-1243.

[3] S.X. Zhang, J.B. Li, J. Cao, H.Z. Zhai, B. Zhang, J. Europ. Ceram. Soc. 21 (2001) 2931-2936.

[4] M. K. Jain, M. C. Bhatnagar, G. L. Sharma, Sens. Actuators B 55 (1999) 180-5.

[5] C. Cosentino, E. N. S. Muccillo, R. Muccillo, Sens. Actuators B, 96 (2003) 677-683.

[6] C. Cosentino, E. N. S. Muccillo, R. Muccillo, J. Sol-Gel Sci. Tech. 37 (2006) 31-37.

[7] Y. Park, Y. H. Kim, and H. G. Kim, Mater. Sci. Eng. B 40 [1] (1996) 37-41.

[8] A.E. McHale and R. S. Roth, J. Am. Ceram. Soc. 66 [2] (1983) C18-C20.

[9] A.E. McHale and R. S. Roth, J. Am. Ceram. Soc. 69 [11] (1986) 827-32. milling of $\mathrm{TiO}_{2}$ and $\mathrm{ZrO}_{2}$ decreases the sintering temperature for preparation of pure ceramics without additives. The variation of ceramics porosity from highly porous ceramics to almost completely dense ceramics was tailored by changing the sintering temperature from 1100 to $1400{ }^{\circ} \mathrm{C}$.

The humidity sensing ability of porous $\mathrm{ZT}$ ceramic was identified by investigating the electrical conductivity at different humidity. Highly porous ZT ceramics sintered at 1100 and $1200{ }^{\circ} \mathrm{C}$ showed significant increase of electrical conductivity over five orders of magnitude with increasing relative humidity from $33 \%$ to $75 \%$, thus indicating promising application as humidity sensors. On the other hand, electrical response of ceramics sintered at 1300 and 1400 ${ }^{\circ} \mathrm{C}$ is independent on atmosphere conditions due to lower porosity of ceramics.

\section{Acknowledgements}

The authors acknowledge Luka Pavić (NMR Center, Ruđer Bošković Institute) for performing impedance spectroscopy measurements. This work was supported by Croatian Ministry of Science Education and Sport, projects: "Physics and applications of nanostructures and bulk matter", 098-0982904-2898, "Influence of structure on electrical properties of (bioactive) glasses and ceramics", 0980982929-2916 and "Interaction of minerals and environment", 119-0000000-1158., the work in Berlin is financially supported by Croatian-German bilateral project and Max Planck Society.
[10] Gajović, K. Furić, S. Musić, I. Djerdj, A. Tonejc, A. M. Tonejc, D. Su, R. Schlögel, J. Am. Ceram. Soc., 89 [7] (2006) 2196-2205.

[11] Gajović, I. Djerdj, K. Furić, R. Schlögl, and D. S. Su, Cryst. Res. Technol., 41 [11] (2006) 1076-1081.

[12] J. Rodriguez-Carvajal: FULLPROF-A program for Rietveld Refinement. Laboratorie Leon Brillouin, CEA-Saclay, France, 2000.

[13] P. Thompson, D. E. Cox, and J. B. Hastings, J. Appl. Cryst., 20 [2] (1987) 79-83.

[14] Djerdj, D. Arčon, Z. Jagličić, M. Niederberger, J. Phys. Chem. C 111 [9] (2007) 3614-3623

[15] Djerdj, A. M. Tonejc, J. Alloys Compd. 413 [1-2] (2006) 159-74.

[16] M. A. Krebs and R. A. Condrate Sr., J. Mater. Sci. Lett. 7 (1988) 1327-1330.

[17] F. Azough, R. Freer, J. Petzelt, J. Mater. Sci. 28 (1993) 22732276. 
[18] V. Ličina, A. Gajović, A. Moguš-Milanković, I. Djerdj, N. Tomašić, D. S. Su, J. Am. Ceram. Soc. 91 [1] (2008) 178186.

[19] K. P. Biju, M. K. Jain, Sens. Actuators B, 128 (2008) 407 413.

[20] Tonejc, Acta Chim. Slov., 49 (2002) 1-28.

[21] B.M. Kulwicki, J. Am. Ceram. Soc. 74 [4] (1991) 697-708. 